\title{
What Killed Moritz Erhardt? Internships and the Cultural Dangers of "Positive" Ideas
}

\author{
Bogdan Costea*, Peter Watt**, and Kostas Amiridis* \\ *Lancaster University, Lancaster, UK; ${ }^{* *}$ York St John University, York, UK; \\ b.costea@lancaster.ac.uk
}

\begin{abstract}
Moritz Erhardt's tragic death as an intern at Bank of America Merrill Lynch in August 2013 provides an illustration of the cultural intensity and complexity that has come to imbue internships in higher education degree schemes. We offer an analysis of internships as part of a wider process of dissemination and proliferation of managerial vocabularies and images that underpin certain hyperperformative practices that permeate the powerful cultures stimulated by and sustained in many organizations. We analyze the cultural ground from which such practices might be seen to arise and present an interpretation of how certain "positive" themes and motifs-such as "potentiality", "selfexpression", or "self-realization"-can become dangerous. These categories become dangerous once they are constituted as ideal measures of an unattainable level of performativity which can then become destabilizing and disorienting for any individual's sense of self. In this sense, the paper contributes to the growing body of literature investigating the significance of internships in the new cultures of work characterizing the broader context of neoliberalism.
\end{abstract}

Keywords: internships, management, performativity, employability, self-actualization, self-realization, potential, work culture, soft capitalism

\section{Introduction}

This paper begins with a section discussing the tragic episode in which an intern lost his life in a direct attempt to demonstrate his passion and commitment to a financial institution in order to secure a future position in it. In the second part (sections 2 and 3 ), we analyze how internships have become part of a much more extensive cultural process in which management vocabularies and images seek to mobilize certain values and inclinations that reach deep into the sensibilities of the current young generations. Finally, in sections 4 and 5 , we provide an interpretation of how management is able to use broader cultural motifs and tendencies in such a way that they become indistinguishable from two central values of our time: "self-expression" and "self-realization" (see also Rose 1999a, 103-119).

We consider the ways in which internships have become regimes connecting certain cultural ideals and promises that have the capacity to mobilize extreme forms of practical engagement with work and organizations. Even though internships may appear to be relatively limited episodes of a working life, we will try to show how they are part of a cultural process in which management and business constitute ways of defining what an individual might be worth, and thus how management ideas play an increasingly subtle and far-reaching role in relation to the self.

In an extensive autobiographical interview, the distinguished philologist George Steiner made a comment, which seemed (and still seems), at first sight, to capture very well a sense of loss of cultural direction and a disoriented system of values:

The young in Europe have never been as hopeless [...] [They have] no sense of an ideology, no sense of any political or utopian future [...] Never forget that if you don't commit great creative mistakes when you're young the rest of your life is largely wasted. You have at least lived the essential passion of commitment which should be that of the young. There is nothing of the kind today. Nobody is going to die for a hedge-fund, nobody is going to die for the enormous entertainment industries, for the mass media, for the athletic worship-which is all the young have. (Steiner 2007) 
It seems so unproblematic to agree with Steiner's comment and its formulation. It seems especially easy to grasp the idea of an unwillingness to "die for" what amounts to a set of hollow cultural objects and institutional sites which claim exclusive attention and yet are just as easy to dismiss on grounds of their apparent worthlessness. And yet, we will try to argue, there is a serious danger accompanying this very manner of dismissing a cultural process that seems, despite its alleged vacuity, to be still able to mobilize the energies of contemporary youth. Who would declare his or her willingness "to die for a hedge-fund"? Probably not a single individual.

Nonetheless, to take this statement at its face value would also leave out, in our view, the other side of the phenomenon Steiner seeks to elucidate: the fact that all those hollow, empty sites currently claiming the passion and commitment of the young are actually capable of mobilizing something that Steiner does not account for, namely, their power to take individuals willingly to the limit of their own capacities. Steiner appears unable to see that hedgefunds, entertainment products, and certainly the manifold forms of advertising and social media are capable of formulating a new kind of promise which can, in the current cultural context, become the ground for intense, passionate, and dangerous personal engagement (see also Ewen 2008). What Steiner overlooks is that these institutional and discursive sites are permeated and sustained by a political orientation which, whilst not conforming to the traditional forms he invokes, has nevertheless become an equally powerful force in the mobilization of youth and its energies towards an "essential passion of commitment."

In the spirit of Michel Foucault's (1970; 1980) and Nikolas Rose's (1999a; 1999b) analyses of the rise of neoliberal regimes of power, however, we argue that the system of ideas circulating throughout the sphere of management has acquired far more subtle and dangerous forms of dissemination and communication. The domain of internships, as one instance amongst many, shows how a set of discursive themes (such as potentiality, performativity, self-development, or self-actualization) makes possible not only the diffusion of their own power throughout the culture of work organizations, but their very insertion in the private, intimate domain of the self (also discussed by Gregg 2011, albeit with a different focus). As shown by Rose, the context of employment has come to be precisely a place where "[t]he division of work and life has not only become blurred at the level of reality, it has also become permeable at the level of images and strategies" (1999b, 158). The result has been the rise of a performative culture that surrounds work but also goes well beyond it, certainly now in the culture of higher education, a culture characterized by "a more dispersed, but more intensive, inscription of the obligation to work into the soul of the citizen, not a reduction of the principle or ethic of work but, in many ways, its intensification" (ibid.).

Perhaps what makes graduate internships notable, as part of the contemporary labour market, is the way in which they illustrate Karl Marx's intuition that the production of value in the work process comes to be displaced, in the context of modern capitalism, from the production of "direct use values" and "subjugated", in its "every moment", to "exchange" as such (Marx 1973, 408). Whilst we cannot fully develop this aspect here, it is important to make this insight explicit. It indicates a way in which it becomes clearer how pure performativity in work-in other words, the pure acting out of the appearance of work-becomes the basis upon which the value of work is perceived and ascertained. In Marx's understanding, "Commerce [...] appears here [...] as an essentially all-embracing presupposition and moment of production itself" (ibid.). "Exchange", expressed in "commerce" as an overwhelming feature of capitalism, becomes the manner in which performativity begins to dominate the understanding of value in the current context of capitalism and thus becomes a defining parameter of work as such.

\section{The Case of Moritz Erhardt}

At 8:30pm on Thursday, 15 August 2014, Moritz Erhardt, a twenty-one year old student intern at Bank of America Merrill Lynch, was found dead in the bathroom of his shared accommodation in London, England. Colleagues raised the alarm when Erhardt did not turn up for a 2 
pm meeting that day (Day 2013). The cause of Erhardt's death was eventually considered unsuspicious and has since been understood as the result of an epileptic seizure, a seizure believed by the coroner investigating the case to have been triggered by a prolonged lack of sleep (Kennedy 2013).

Erhardt was a German student from Staufen who, at the time of his death, was coming to the end of a seven-week placement with the bank. Toward the end of his summer internship, Erhardt decided to work three days and nights in a row (roughly 21 hours of 24) in order to show his commitment in the hope that he will be offered a full-time position at the end of his studies. This hope has been captured by the notion of "hope labor" by Kathleen Kuehn and Thomas Corrigan $(2013,9)$, which explores the inherent tensions between working in the present "for free", as it were, in the hope that "future employment opportunities may follow." Unaware that he had already shown himself to be so capable that the bank was indeed preparing to offer him a full-time job as a $£ 45,000$ per year analyst after his graduation, Erhardt engaged in a practice well-known amongst interns and other employees in the sector: the "magic-roundabout":

Over a 72-hour period, he got a taxi back from the office to his flat in Bethnal Green, east London, at around 5am each morning. He would then shower briefly before returning to his desk. This exhausting ritual is known in banking circles as the "magic roundabout"so-called because the taxi driver will sometimes wait outside while an intern washes, puts on a fresh shirt and re-emerges blinking in the dawn light. (Day 2013)

In another report, a fellow intern "claimed that Mr. Erhardt '[...] apparently pulled eight allnighters in two weeks. They get you working crazy hours and maybe it was just too much for him in the end"' (Gallagher 2013).

The reports of Erhardt's death did not have much to go on other than the subsequent interpretations offered by those who knew him; however, these too are limited by the fact that Erhardt was not doing anything new within the work culture characterizing this particular bank, nor was his own tendency to work long hours new in itself: "Users of the popular finance blog wallstreetoasis.com insisted Mr. Erhardt regularly worked long hours, with his final three days consisting of 21-hour stints in the office" (Gallagher 2013). Moreover, nothing out of the ordinary was noted perhaps also because Erhardt did not declare his condition to anybody around him in London, including his employers. Jürgen Schroeder, Erhardt's Development Officer at the bank, told the inquest that no one at the bank had been aware of the intern's history of epilepsy. He told the inquiry that Erhardt was highly rated, well-liked, and was going to be offered a job, adding that "he had hinted as much to Erhardt the day before he died" (Malik 2013).

The reports noted that Erhardt was a bright and handsome young man who had a tendency to work hard and party equally hard. His father, Hans-Georg Dieterle, a psychoanalyst and "life coach", warned him about the possibility of exhaustion, "but, like many young people, Moritz took parental advice lightly" (Day 2013). Yet this was no simple adolescent refusal; rather, his father explained, Erhardt was moved by a more fundamental sense of good intention: "He wasn't just interested in the money. He wanted to do good in the world. I've been sorting through some of his things and I found a quote from Marilyn Monroe he'd made a note of which went, 'I don't want to make money, I just want to be wonderful,"' his father said (ibid.).

However, the reports note that his father told everyone that the bank's staff could not have been more supportive in the aftermath of Erhardt's death, and that he does not blame them for not spotting the warning signs earlier. If there was any sense of anger, Mr. Dieterle said, "it would only be 'with Moritz for not having taken care of himself" (ibid.):

He can imagine, he says, that part of what Moritz loved about the work was the intensity and the esprit de corps that developed during those long days and nights in the office. He compares it to the endorphin rush experienced by long-distance runners or mountaineers who push themselves to climb further without oxygen. The bank wasn't exploiting his son, he insists. Instead, Moritz "was exploiting himself." (ibid.) 
This analogy was professed in a similar way by a Deutsche Bank executive interviewed for the Harvard Business Review: "My work gives me this adrenalin rush. Like a drug, it's irresistible and addictive" (Hewlett 2007). This tendency to respond to the demands of highly pressured roles by participating in long-hour cultural regimes of work has been categorized as "extreme work" (Hewlett and Luce 2006). Internships have become part of this tendency and the reports following Erhardt's case have revealed the widespread nature of long working hours and its close connection with high levels of competitiveness amongst interns and graduates. Erhardt was indeed seen by those around him precisely in this light: he was described by them as a "superstar" (Malik 2013); but he also saw himself in these terms: "... according to his biography on the social media platform Seelio, Erhardt had spoken about his 'highly competitive and ambitious nature' and shown all the outward signs of wanting to be a high achiever and driving himself to that end" (Malik 2013).

However, what emerged at the same time was that the culture of long hours and the more extreme practices that arise from it are not rejected by those who engage in them, rather they often stem from their own initiative and are not elements of formal management systems:

One City intern, who wanted to be known only as Alex, told the Guardian that working for more than 100 hours was normal, but said that despite the pressures he and other interns enjoyed the experience. "On average, I get four hours' sleep about $70 \%$ of the time ... [but] there are also days with eight hours of sleep", Alex said. "Work-life balance is bad. We all know this going in. I guess that's the deal with most entry level jobs these days." He added that despite the amount of time spent in the office, he "enjoyed it greatly."

Alex said it was not uncommon for interns to leave the office in the small hours in a cab only to have it wait outside their flat while they showered, changed and returned to the office. But he said that the practice, known as "the magic roundabout", was an exercise in comradeship. "It's more like a college all-nighter; everybody has to do it. It is more fun that way."

Abdurrahman Moallim, 21, a recent intern at a major multinational bank, said there was an element of one-upmanship involved in working flat-out. "All-nighters are often worn as a badge of honor-it's common for interns to brag in the morning about the long hours they've worked the night before. Everybody wants to show they have what it takes to succeed in an industry which demands stamina." (Malik 2013)

In the end, perhaps the key comments remain those of Erhardt's father: he saw in Erhardt's death an expression of an internal drive expressing his son's own sense of personal direction and aspiration. But is it all that simple to interpret what happened to Moritz Erhardt and to see the significance of his passing? Erhardt's intense involvement in his summer internship seems to have been more than a mere exception. Rather, he internalized an overpowering culture of performance whose dynamic is much more equivocal than could be deciphered if we allow his drama to remain understood as a mere "industrial accident." The entanglement of self-declared personal aspirations with cultures of extreme office work encouraged by corporate institutions in various sectors makes the question "what killed Moritz Erhardt?" not as simple as any one-sided answer might make it seem: Was Erhardt exploited by the banking sector? Or did Erhardt exploit himself? The problem is that both these questions are not helpful in this formulation. Both presuppose a known subject (either the bank, or Erhardt) and a known predicate (exploitation); and both presuppose that it is possible to operate a clear separation between one subject and the other, between one sphere of interests and the other; both can be reduced in fact to the formulation: "Who killed Moritz Erhardt?" And this is the most tempting one, because it is the simplest: it provides a crime and a victim. To such a question there can be but a single answer, one predicated moreover upon an unequivocal logic: as the victim of an institutional practice, Erhardt can only be innocent. Once the culprit is found, the complexity of conditions that made possible the entire story would disappear leaving a simple, cleansing, and redeeming picture in its stead. We would then "know", as it were, who is to blame, who is "good" and who is "bad." Unsurprisingly, in the current circum- 
stances, the reports of the case in the ensuing months were clear: the bank and the financial sector are responsible for generating and tolerating a culture of work around internships and early graduate career positions which allow rather punishing forms of individual behaviour.

More importantly, that "who" would be confined to a particularity, to a singular context in which an "error of judgment" occurred and which then requires a correction. Erhardt's case would not represent "us" then, and by "us" we mean a more universal set of possible conditions and values in the name of which, to speak against Steiner's statement, there may well be a form of more generalized willingness to "die for a hedge-fund." In other words, we will try to show that simply asking the question "who killed Moritz Erhardt?" in order to dispense with this particular case would be to miss the opportunity to ask instead "what killed Moritz Erhardt?" We argue that this would provide a different kind of starting point in an interpretation of the conditions of possibility that seem to bring together and align to a significant cultural extent, the values and orientations of interns and graduates such as Erhardt, with the values and orientations of corporate cultures. In other words, one of the questions which seems to us to be equally legitimate, following on from Erhardt's tragic experience, can be formulated in the following terms: what were the conditions in which he took himself to the limit, and how was an internship the place of testing boundaries, rather than adhering to them?

\section{3. "Unlimited Plenitude" as an Underlying Feature of Internship Culture}

The answers to these questions can take various forms. On the one hand, it can be argued that Erhardt's tragic end was driven by a specific and unfortunate set of physio-pathological factors, combined with a failure on his behalf to manage his own physical condition, or to ask for help. On the other hand, it can also be argued that it was a failure of the work organization to provide systems of containment of possibly harmful exertion: a system of time management, perhaps. In both cases, Erhardt's case would be regarded as an unfortunate "industrial accident"-an accident caused by a badly managed system of production. It is important to note that these possible responses have one thing in common: the premise that something was lacking, that there was an oversight somewhere or other-that systems of collective and individual management have failed.

However, we propose it is worthwhile exploring what might be revealed if we change this premise and look at this case from a different angle. Instead of trying to find the dangers caused by failures and shortcomings of management systems, we suggest that it is just as important to analyze the dangers of those cultural processes in which new management discourses and communications processes succeed. That means that we might be witnessing, in the case of Erhardt, the outcome of a particular way in which managerial themes have succeeded in positing and proliferating an image of work and human resourcefulness through which an individual is aligned to an ideal type characterized by what might be termed unlimited plenitude. As we seek to illustrate in this section, management vocabularies and images surrounding internships and graduate jobs have grown to an unprecedented extent precisely around the themes of plenitude. As we have shown elsewhere (Costea, Amiridis, and Crump 2012), the motifs of individual potentiality, performativity, and perfectibility suffuse the culture of graduate work. "Unlimited plenitude" aims to capture what Foucault termed a discursive "strategy": a "theme" (rather than a "concept") which connects the different ways in which various media channels construct an idealized image of the intern as a subject who is not only characterized by an abundance of potential and possibilities, but is also driven by a sense that this abundance can and indeed must be endlessly sustained (Foucault 1972, 64).

The word "plenitude" comes from the Latin plenus which means full and from which derives the word plenitudo which denotes completeness and abundance (Lewis and Short $1879,1386-1387)$. It is important to pause upon these two meanings. As we will try to show in this section, our argument is that what happened to Erhardt was not simply an experience of his own "self" as being abundantly full of possibilities. Rather, it is not only that he thought of himself as abundantly capable of handling work to the limit, but it might be the case of a more subtle and more crucial cultural mechanism that triggered Erhardt's carelessness with 
himself and his condition: the idea that he can actually go beyond the limit. What he seems to have succumbed to is a mentality whose ground is that he can hold and live in the name of the idea that he has no limits, that there is always "more" to be brought out, actualized, from the plenitude of his potential. Erhardt did not feel complete, formed, full-he rather seems to have felt compelled by, and towards, a far more dangerous horizon: a horizon through which managerialism has succeeded to represent work as a form of ultimate self-empowerment, self-expression, and self-realization. This is an argument pursued by Kathi Weeks (2011) in her analysis of the ways in which work is not simply represented as a necessity, but also as a "good" in itself: working more, performing more, means at the same time a chance to become more involved with the so-called "realization" of one's possibilities.

How can we explain this success of managerial culture? How could management themes of such dangerous and tragic intensity have become so subtly inserted in the context of internships and graduate positions? Erhardt's life and death thus enable another kind of question: not just how many failures of management can be detected here, but rather how can we understand the very success of managerial, organizational, and societal cultures which is expressed in their ability to reach into the deepest recesses of the modern soul, into its very sense of mortality?

A further comment must be added here. The first internal response of the bank Erhardt worked for was to set up a panel of senior managers to review the entire case. The outcomes of this review were presented in a memo to staff sent on 10 January 2014 in which Bank of America Merrill Lynch begins to address the question of how to maintain its "effectiveness" whilst finding some way of limiting the work regime driven by the bank's culture and practices (Wright 2014). The memo appears, unsurprisingly, confined to some measures of work reduction, further "support" for "work-life balancing", and obligatory days off. However well-intended these measures might be, what appears to be at stake here is not a failure of management systems and principles. In fact, the problem organizations such as this bank face is not their inability to "motivate", but their excessive ability to mobilize the will to work: "empowerment", it seems, is not lacking -it is, it seems, all too successful.

In order to understand how internships have become so important, it is necessary to contextualize their growth in the context of the rise of the "graduate" as a central dimension of the corporate labour market. Over the last two decades, the "graduate" has become a recurrent figure and a core motif in management discourses and in contemporary culture more broadly. Significant efforts in official public policy, both in the "old" economies of the West, but also in the emerging economies of the East and South, have made the idea of having (at least) a higher education degree as an almost sine qua non condition of full participation in what began to be projected in the 1990s by highly prominent political and business figures around the world as the coming "society of knowledge"-termed variously as "the information superhighway" (first coined by Al Gore Jr. in 1978), "Infobahn" in German circles, a concept which settled later in the much broader and more significant concepts of "knowledge economy" and "knowledge society". The extent of the importance of these terms for the evolution of the "graduate" became manifest in targeted policies to increase numbers of school leavers joining higher education, of which one of the more notorious examples was New Labour's promise in the 1997 Manifesto for the General Election that "half of eighteen year olds to go into university studies" (Labour Party, Great Britain 1997).

As management circles also became intensely preoccupied with capturing the rise of what appears to be the "new economy" (Drucker 1994, 2002; Böhme and Stehr 1986; Nonaka and Takeuchi 1995; Castells 2011), an important organizational trend became established: the steady separation of a new system of job allocation for graduates and the consolidation of graduate schemes across all sectors of activity and industry. This consolidation took place through the steady growth of the "graduate scheme" as a new form of employment, whose explicit focus is the "graduate" (see, for example, one of the core sources in Europe and the UK: Birchall 2011; 2013). These are a kind of apprenticeship programme structured through a combination of work and training and are targeted to recent graduates. They are highly competitive, operating in the context of a normal open labour market. They are offered mainly by large employers; they may last for a period of three months to three years, and, on suc- 
cessful completion, the incumbents normally tend to be offered permanent positions and sometimes a professional qualification. In many sectors of the economy, private and public organizations, large, medium, or small, now follow this path and generate such schemes to the extent that they have now become nearly obligatory elements of employment policies and practices. Companies vie for the attention of "graduates" in various contexts and especially seek to take this new form of labour market competition to the university campus itself. In this context, internships become an almost obligatory point of passage towards a graduate job. In fact, in many cases the internship is a necessary condition for any realistic chance of securing employment.

Some of the most recent available data show that this pattern of employment becomes of further importance to any future graduate through the fact that 40 percent of all job offers in these highly sought-after schemes (e.g., Aldi, Accenture, and PricewaterhouseCoopers, but also the Civil Service in the UK, or charities such as Cancer Research UK) are made through internships that are part of degree programs (Paton 2014). This trend is significant because it has led to the emergence of a cultural machinery of promotion and recruitment, which has, in turn, generated an inextricable entanglement of work and study. This extensive preoccupation with work, rather than the preoccupation with study as such, has accompanied the rise of the "graduate" as a figure of prime importance even before university studies are concluded. It is in this reordering of priorities that internships have come to occupy such a prominent place in the expectations of both students and academic institutions themselves, and is central to what has come to be known as "employability".

\section{Internships in the Culture of Soft Capitalism}

From every corner of secondary school career advisory services, colleges and universities, from various notice boards and websites, to family dinner tables, as much as in governmental policy documents, current generations of students are surrounded by the exhortation to pursue academic study as a path to becoming employable, as well as a path towards a promised future of personal development, self-actualization, and success. Rebecca Boden and Maria Nedeva note that the narrow sense of what a graduate has to do to become employable in terms of "simply gaining and retaining fulfilling work" has been superseded by an expanded sense seized upon by Lee Harvey as "the propensity of the graduate to exhibit attributes that employers anticipate will be necessary for the future effective functioning of their organization" (Harvey 2000 in Boden and Nedeva 2010). And there is no shortage of statements that describe and display these attributes, so much so that it can be argued that the images of the ideal type that comes under the label "graduate", and which includes the culture of internships as its preliminary stage, have come to constitute a media genre in itself both in management discourses and in popular culture.

The proliferation of these images is relatively new in its intensity and omnipresence. It seems to have emerged over the last decade or so. Yet the complexity of this genre and its manifold forms of expression has grown to such an extent that they became key reference points for what it might mean to have the sense not just of work, but of a "worthwhile life" as a whole. This sui generis media genre takes multiple forms: highly complex job advertisements, even more complex internet recruitment campaigns, dedicated collections of job and internship opportunities (see, for example, The Times Top 100 Graduate Employers annual collections), specialized consultancies and counselling publication series, dedicated newspaper columns, but also school and university "employability" services, and its apparatus is self-disseminating in the sphere of social media. This plethora of means is suffused with images of work and personal success whose status has now become iconic. Through the diffusion of such images, texts, and practices, the "graduate" is configured as an ideal of personal achievement and, more importantly, as a process of self-development and self-realization. The promises made by management discourses are significant and have already weighty cultural consequences.

A survey of these cultural effects has been produced by Carina Paine and Sue Honore for the Institute of Leadership \& Management at the Ashridge Business School in 2011 (Paine 
and Honore 2011). It follows a series of previous analyses of the cultural phenomenon termed "Generation Y" by the two authors. In this survey, Paine and Honore outline a series of themes that provide important starting points for thinking about the nature of the ideal type of the "intern" and the "graduate" in the contemporary imagination.

To begin with, Paine and Honore identify a tendency to expect that higher education degrees will offer a particular life direction and enable the definition of a path in life. Students and aspirants enroll in higher education programs thinking that the process will uncover numerous possibilities for both career growth and for a direction in life. They show that current generations of students and graduates are strongly motivated not just by salary levels but also and especially by "status and career advancement, and expect rapid progress in these areas" (ibid., 2). Such expectations are significant in terms of their intensity and rhythm of career mobility. They found that " $56 \%$ of graduates expect to be in a management role within three years of starting work, while $13 \%$ of graduates expect a management role within a year" (ibid.). Inevitably, they also found that more than a third of graduates find their sense of direction somewhat confounded by the limits of organizational environments with respect to such expectations. The impression that being a graduate, especially on a management training scheme, ought to be accompanied by an almost automatic entitlement to promotion, power, and authority is not, indeed could not be, borne out by entry-level positions, yet a sense of entitlement appears to be more prevalent amongst members of Generation $Y$ than previously.

The second core aspect of Generation Y's expectations of work is "a high degree of freedom and autonomy" in organizational settings: "Graduates want their organizations to: respect and value them (43\%); support them with career progression (36\%); trust them to get on with things (35\%); and communicate well with them (34\%)" (ibid., 3 ). This is combined with the expectation that organizational membership functions more in a cultural paradigm of friendship rather than mere hierarchical authority. Paine and Honore found that graduates of Generation $Y$ prefer to see their superiors as coaches, mentors, and friends: 'Graduates' ideal manager is a coach/mentor $(56 \%)$ or friend $(21 \%)$ rather than someone who directs $(8 \%)$ or examines and audits (2\%)" (ibid., 2-3). Moreover, the high expectations of personal progress in work are combined with the tendency to see the future in terms of high mobility. Students today, whilst being broadly engaged at work, are not offering "long-term commitment to their employer, with most looking to move on within two years" (ibid., 3). The expectation of personal independence and unrestrained mobility in employment is, at the same time, combined with the demand that every organization will provide respect and trust as well as open and "friendly" communication and relationships. Paine and Honore conclude with an essential point: the images of what it means to be a graduate, of what work as a graduate entails, and of the general horizon of personal life and "progress" have come to be shaped by a sense of "ambition, expectations and focus on the self [that] are part of Generation Y's fundamental make-up" (ibid.). In essence, whilst not explored explicitly in the report, Paine and Honore's work can be interpreted as showing how the cultural expectations of students tend to revolve around four core themes: the sense of a promised path through life, the sense of freedom as a promise and requirement to feel "fulfilled", the expectation of "personal progress" as a constant feature of "graduate" life, and the ambiguous sense that to be a "graduate" becomes both a source of inexhaustible personal mobility as well as the platform for always finding a "home" anywhere where life might take an individual (i.e., the sense that organizations can be expected to function as contexts of trust, respect, and friendship). How did such complex and overestimated expectations come about? What processes prepared their emergence?

To answer such questions, it is important to return to Paine and Honore's survey in which certain aspects of the phenomenon they describe cannot, by the nature of their research, be either apprehended or interpreted within their own empirical data collection process (2011). Their survey focuses the attention on students as isolated participants responding from within an individual's own sense of the present. The response appears to represent the respondent's consciousness over and against a broader context from which he or she is separated. The effect of this positioning is that the image generated by the research frames and focuses 
responses as purely interior reflections and perceptions. As a consequence, the authors make an important argument: they focus on the apparent gap between the expectations of Generation $Y$ and those of their managers and organizations. The outcome is that students' expectations are characterized by a novelty that both surprises and confounds the expectations of their future institutions. It seems that Generation $Y$ brings with it an unprecedented kind of cultural matrix in which a new set of values, ideas, and attitudes are manifest. The authors thus run the risk of missing a key cultural dimension of their research: namely, that the responses provided by Generation $Y$ graduates are not separate from, and simply internal to, this demographic group. They are not separated from the broader culture of management which has emphasized over the last several decades precisely the values that Generation $Y$ now embraces in relation to work. This is evident in the authors' conclusion noted above: "ambition, expectations and focus on the self are part of Generation Y's fundamental make-up" (ibid.).

If this is the case, then this conclusion almost inevitably draws attention to the continuity of values shared between Generation $Y$ and its predecessors, rather than to a gap between them. A more systematic picture of the relationship of continuity between Generation $Y$, contemporary cultural values as a whole, as well as managerial values and tropes in the last three decades is drawn by Paul Heelas (2002). He explores the way in which the values described above as specific to Generation $Y$ actually developed throughout the latter half of the $20^{\text {th }}$ century as part of a much deeper cultural process characterizing secularized modernity. Heelas demonstrates, using Tipton's analysis of four "styles of ethical evaluation" and their transformation since the 1960s (Tipton 1984), that the current period is characterized by a turn both in culture as a whole as well as in management thinking towards what Heelas terms "the ethics of self-work" (Heelas 2002, 79), the ethics of the expressivist culture of the self that became dominant in the last four or five decades. The "focus on the self" noted by Paine and Honore is thus correct but their interpretation as a novelty is historically inaccurate. As Heelas shows, the focus on the self is a tendency that runs deeper in contemporary Westernized culture, which begins to explain more precisely why Generation Y's attitudes towards, and expectations of, work are not split from the existing cultural context. Exploring the meaning of the "ethics of self-work", Heelas shows that it initiates a specific mode of thinking, or mentality, regarding what it means to be an "individual today." He shows that the sources of both authority and value rest with the "self", as seen in the following light:

Not the self as constituted by consumer culture, but the self as a self which considers itself to be something more, something much "deeper", more natural and authentic than the self of what is taken to be involved with the superficialities of the "merely" materialistic-cum-consumeristic; the self as a self which has to work on itself to enrich and explore itself, in the process dealing with its problems. The self-work ethic, that is to say, treats work as something to be valued as the means to those ends espoused by expressive or therapeutic culture. (ibid., 80-81)

He proceeds to demonstrate the extent to which the values of the self-work ethics correspond to the values of a new style of managerial approach for which he uses the category of "soft capitalism" in which personal involvement, creativity, learning, development, culture, and knowledge become central attributes that bestow value upon the working subject:

Soft capitalism involves narratives, more specific discourses, and practices to do with enhancing commitment and motivation; identifying and unblocking "barriers" to success; seeking identity (what it is to become/be a good manager or telephone call center operative, for example); working as a team or as a company; exercising responsibility or initiative; engaging in work ethics, emotion work; "closing the sale"; believing in one's product; and so on. (ibid.)

In other words, Heelas argues: "We are in the land of what can be called the exploratory mode of soft capitalism. Work, that is to say, is taken to provide the opportunity to 'work' on 
oneself; to grow; to learn ('the learning organization'); to become more effective as a person" $(2002,83)$.

As a result, it becomes important to re-contextualize the cultural place of the intern within the contemporary value system as a whole. It is therefore problematic to isolate students and interns of any current generation from this complex whole and to set them apart as "new" carriers of unprecedented or surprising mentalities. Rather, the "intern" becomes a figure in which core values of our epoch coalesce, and not simply as a generational or demographic section of the population, or an economic category. It seems more productive to see the intern as a cultural place where core demands regarding work and their attendant struggles are expressed. Hansfried Kellner and Frank Heuberger synthesized these demands in their volume on "hidden technocrats" in 1994; they show that today work is itself expected to be a place that takes into account:

\begin{abstract}
the importance of an individual's quest for an "unfolded" personality; the justified demands for self-realization, autonomy, and authenticity; the prerogatives of the subjective life, emotional well-being, and intimacy against the demands of rationalized industry, with its controlling pressures, coldness, and abstractness; the rights of private over public life; the individual's search for "meaning" in a world that is held to be devoid of meaningful symbols, plausibility, and credibility; the individual's need for "spontaneity", "immediacy", and expression of hedonistic impulses; the importance of creativity and fantasy. (Kellner and Heuberger 1994, 57)
\end{abstract}

This broad context of values, ideas, and mentalities characterizing contemporary culture becomes an important source for understanding how managerial ideals have become integrated in a wider cultural process. On the one hand, management discourses have the power to shape organizational cultures and contexts through their capacity to make promises; on the other hand, however, management is in turn shaped by societal and cultural expectations with respect to how work ought to be organized, and how it ought to be approached.

Seen in this cultural-historical light, Generation $Y$ does not think about work in ways that have not already been prepared in the last three or four decades, both within management vocabularies and outside them (Rose 1999a; 1999b). The gap between generations begins to fade when we consider that the cultural apparatus through which the themes of personal potential, self-expressivism, and self-realization have been perpetuated from the 1960s onwards and eventually taken over by managerialism though the 1990s and 2000s (Tipton 1984; Thrift 1997, 2000; Heelas 2002). So what really happened to Erhardt in the cultural context and pressures of his high-flying internship?

\title{
5. The Dangers of the "Positive" and the Cultural Power of Self-Realization
}

In this section we want to draw attention to the fact that interns (and graduates more generally) face a more ambiguous and complicated set of cultural forces when joining organizations today. These cultural forces express what Kellner and Heuberger, as well as Heelas and others, have seized upon: that the self-work ethic and the self-exploratory mode of work and performativity have become omnipresent in the "new economy" (Thrift 2000).

Essentially, as shown elsewhere (Costea, Amiridis, and Crump 2012), interns become part of a cultural nexus in which personal success in work is a function of what we have termed the principle of potentiality: a representation of the human subject as capable of becoming always more than what she or he is. Work has come to be represented as a process of freeing up, liberating, and mobilizing an individual's inner qualities, qualities which are supposed to be always ready to be actualized. The managerial genre of the intern, crystallized in the new forms of recruitment materials and in the overall apparatus of employability, contains the promise that work is now a new kind of engagement between individuals and institutions, between private life and public life, between work and non-work, between selfsacrifice and self-realization. In its forms of address to potential interns, managerial culture speaks in a sustained register in which work is presented as a program of personal selfdiscovery. Perhaps a synthetic illustration of this program could make this clear. In the 2009 
edition of the publication The Times Top 100 Graduate Employers (Birchall 2009, 185), the corporations in charge of the nuclear industry in the UK-a group of six public and private institutions, including Rolls Royce for example (Nucleargraduates.com, 2009)—present their internship and graduate schemes in the following form: in the middle of a simple black page, appears a single question: "Who am I?" (At the bottom of the same page, the site nucleargraduates.com indicates the answer: "Explore the exceptional.") This question is the crucial ingredient of the new kind of invitation and promise regarding work which capable individuals like Erhardt can only find impossible to resist. Who can object to the idea that work ought to be the central place where "I" find and express "my" essential humanity? In such artifacts, management discourse articulates both the central ideal of life as well as an inalienable right in contemporary culture: to make one's self what one wants it to be. Through work any candidate can aspire to an always better future, a more fulfilled, self-realized self. It is through this promise that the imagination of potential candidates like Erhardt is captivated by a conception of work represented as a positive opportunity for self-expression and self-realization rather than self-renunciation or repression.

This is how the "Self" (seen in light of Foucault's, Rose's, or Heelas' analyses) becomes reconceptualized as a source of immanent forces and energies, of potentialities which make the "Self" in itself a store of human resourcefulness (Costea, Crump, and Amiridis 2007). The relationship between work and self is thus configured and presented as an "opportunity": the self seems to be given the chance to work upon itself in order to release its own inner potential. The resulting vocabulary, with its now ubiquitous motifs of "creativity", "innovation", "knowledge", "talent", "drive", and "vision", come to be seen and understood as inner possibilities awaiting their exploration and expression, but also as the basis for a cultural demand that work is seen to facilitate. All one needs to do is work hard, develop continuously, and take command of these innate possibilities.

An important historical nuance must be introduced here to explain the power of current images of potential. The portrayal of potential as innate is a subtle shift from the previous uses of terms such as "actualization" or "fulfillment" associated with approaches such as Human Relations, or the Human Potential Movement in the 1960s. In current management discourses, the distinctive attribute of the human subject is that potential is predicated upon an inner plenitude, an abundance of qualities already possessed by the individual. The way in which management uses this presupposition has a specific weight: by attributing innate plenitude to each and every individual, managerialism creates a platform from which it issues the demand that the individual engages with her or his potential, and takes control of its expression and mobilization. This way of portraying the human subject is different than, for example, Mayo's understanding which revolved throughout his work around the dangers of an inner subjectivity which he saw as irrational, emotionally unstable, and a threat to the moral order of work and the organization (O'Connor 1999, 225). Moreover, what he called the "mental hinterland" of the workers (ibid.) posed the further danger of spilling over into the social fabric of organized life, and lead to a collectivity contaminated by maladjustment. Against this psychological danger, the role of management was seen by Mayo in therapeutic terms, acting in the name of enlightened reason to tease out, through the "counselling interview", and control the dark side of the psyche.

The Human Potential Movement manifest in Erhard Seminar Trainings (EST, widespread in the US from the 1960s to the 1980s, and now converted into "life coaching"), or D'Aubigny's Exegesis system (in the UK in the 1970s) similarly conceived of the interiority of the human subject as a source of fears and problems, anxieties and traumatic content, which had to be forcefully, violently at times, evicted in order to make room for a rebirth, for a metamorphosis into a new "self." "Your lives don't work, assholes. Otherwise you wouldn't be here" was the irrefutable introductory statement of EST seminars (according to Tipton 1984, 177). The dynamic of the Human Potential Movement revolved around an emptying of the subject rather than a positing of its inner qualities and potential as source of personal value.

However, as Rose has shown, when analyzed in light of Maslow's, Rogers,' Frankl's, or Fromm's contributions, followed by Argyris, Vroom, or Herzberg, we can establish a substan- 
tive affinity between them and the managerial discourses of the intern today (Rose 1999b, 110). A clear and direct connection can be found in Maslow:

Now let me try to present briefly and at first dogmatically the essence of this newly developing conception of the psychiatrically healthy man. First of all and most important of all is the strong belief that man has an essential nature of his own, [...] that he has needs, capacities and tendencies [...] some of which are characteristic of the whole human species, cutting across all cultural lines and some of which are unique to the individual. These needs are on their face good or neutral rather than evil. Second, there is involved the conception that full healthy and normal and desirable development consists in actualizing this nature, in fulfilling these potentialities, [...] growing from within rather than being shaped from without. Third, it is now seen clearly that psychopathology in general results from the denial or the frustration or the twisting of man's essential nature. By this conception what is good? Anything that conduces to this desirable development in the direction of actualization of the inner nature of man. [...] What is psychotherapy, or for that matter any therapy of any kind? Any means of any kind that helps to restore the person to the path of self-actualization and of development along the lines that his inner nature dictates. (Maslow 1954, 340-341)

Whilst Maslow's conception has been at the center of academic interpretations of work motivation, in terms of its practical deployment in managerial practices, its evolution has been more or less evident over the decades. In the case of current invocations of inner potential in the operation of recruitment and selection of interns and graduates, as well as the commandment to actualize this potential, the Maslowian heritage is perhaps more discernible than ever. An important aspect of this conception is the assumption of the moral "good" of self-actualization and the way in which managerialism seeks to position itself as opening up a path for it.

The essential aspect, which must be highlighted here is that the invocations of potentiality and plenitude function on the fundamental basis that any discussion of the inherent limits of the human subject of work is silenced. The motif of unlimited plenitude revolves around the logic of this silencing, namely as an active denial of human limits. The incessant drive for more performativity, more innovation, more profitability, is the engine of a cultural process underpinned by the denial of human limits.

\section{Concluding Remarks}

Is it possible to answer the question regarding Moritz Erhardt's tragic death as an intern in a high-powered organization: was it an industrial accident, a mere coincidence of terrible misfortunes related to health and work cultures? Of course, it was all of these. Our argument, however, is that there are also other aspects which make Erhardt's story worth reflecting upon and worth bringing into the light of wider tendencies in contemporary management cultures.

We have tried to explore one of these tendencies: the gradual growth of a culture of work focused intensely and unremittingly on the self, a culture which becomes obligatory from the very early stage of careers, so much so that internships themselves become a kind of testing ground for the mettle of individuals. In this sense, the original question, what killed Moritz Erhardt?, becomes more complex and complicated. It seems that Erhardt, and so many others like him, are part of a complex process in which management discourses have appropriated the complex imperative of self-realization. This theme becomes a way of projecting work as an opportunity for the self to express itself. And this imperative is dangerous because it cannot simply be dismissed as a managerial "invention." Erhardt legitimately wanted to find what he himself was "made of." "Who am I?" is a question that functions with such intensity because it is our question, one which presses in on each of us with a legitimacy rooted deeper than its recent uses by management. In fact, management becomes able to insert its own demands in the current cultures of work precisely because it seizes upon legitimate aspirations that come from the interiority of the contemporary self. 
When the self is permanently at stake, self-expression becomes a defining mode of engaging both with the interior and the exterior of consciousness, it becomes a process of almost extreme attempts to give a physical performance of the self's interiority, both publicly and privately. This is what seems to undergird the ritual of the "magic roundabout" of sleepless working. Erhardt seems to have been caught right in the middle of contemporary culture: more precisely, in its performative middle, in that place of the contemporary condition where the binding crux of culture seems to have found its most powerful source. That is, Erhardt was caught at that juncture where the "self" manifests its dominion as the overall form which demands to be incessantly performed by each and every individual. The "self" is that cultural form generating the exhortation characterizing nowadays every social and cultural domain: that any concrete individual must express his or her "exceptional", "unique" "potentialities and talents."

The idea that the "l" has to find itself in a search for inexhaustible potentiality and uniqueness changes the terms of the promises made in various social contracts. The work contract becomes perhaps the most important place where a new horizon of promises can take shape in such a way that the result can be the extreme form of engagement to which Erhardt fell victim. Potential, self-expression, performance, self-realization-these are, in our argument, the dangerous cultural forces underpinning what has become a quasi-dogma of contemporary culture: "positivity." And this doctrine seems to feed and sustain managerial culture in a dangerously robust manner.

The case of Moritz Erhardt also presents the opportunity to open up avenues for comparative research and interpretation regarding its specific cultural context and its nature. In this paper, we have not treated it in comparative terms, but it is important to note that it is an event which occurred in the context of an American institution located in the powerful work culture of the City of London financial sector. In other words, this has to be treated as an instance of specific Anglo-American work cultures. In what way does it compare with the cultures of other regions of the world, with other sectors of activity? How these cultural themes are distributed and diffused in various parts of the world would require a systematic comparative analysis that is beyond the economy of this article, but is the next logical step in a future research agenda.

\section{References}

Birchall, Martin. 2009. The Times Top 100 Graduate Employers 2009-2010. London: High Fliers Publications Ltd.

Birchall, Martin. 2011. The Times Top 100 Graduate Employers 2011-2012. London: High Fliers Publications Ltd.

Birchall, Martin. 2013. Times Top 100 Graduate Employers 2013-2014. London: High Fliers Publications Ltd.

Boden, Rebecca and Maria Nedeva. 2010. Employing Discourse: Universities and Graduate "Employability." Journal of Education Policy 25 (1): 37-54.

Böhme, Gernot and Nico Stehr. 1986. The Knowledge Society: The Growing Impact of Scientific Knowledge on Social Relations. Dordrecht: Springer.

Castells, Manuel. 2011. The Rise of the Network Society: The Information Age: Economy, Society, and Culture. Oxford: Wiley-Blackwell.

Costea, Bogdan, Norman Crump, and Kostas Amiridis. 2007. Managerialism and "Infinite Human Resourcefulness": A Commentary on the "Therapeutic Habitus", "Derecognition of Finitude", and the Modern Sense of Self. Journal for Cultural Research 11 (3): 245-264.

Costea, Bogdan, Kostas Amiridis, and Norman Crump. 2012. Graduate Employability and the Principle of Potentiality: An Aspect of the Ethics of HRM. Journal of Business Ethics 111 (1): 25-36.

Day, Elizabeth. 2013. Moritz Erhardt: The Tragic Death of a City Intern. The Guardian. October 5. Accessed November 3, 2013. http://www.theguardian.com/business/2013/oct/05/moritz-erhardtinternship-banking.

Drucker, Peter F. 2002. Managing in the Next Society. New York: St. Martin's Press.

Drucker, Peter F. 1994. Knowledge Work and Knowledge Society: The Social Transformations of this Century. Harvard University Forum. Accessed December 15, 2014. http://forum.iop.harvard.edu/content/knowledge-work-and-knowledge-society-socialtransformations-century. 
Ewen, Stuart. 2008. Captains Of Consciousness: Advertising and the Social Roots of the Consumer Culture. New York: Basic Books.

Foucault, Michel. 1980. Power/Knowledge: Selected Interviews and Other Writings, 1972-1977. Brighton, UK: Harvester Press.

Foucault, Michel. 1972. The Archaeology of Knowledge. London: Tavistock Publications.

Foucault, Michel. 1970. The Order of Things: An Archaeology of the Human Sciences. London: Tavistock Publications.

Gallagher, Paul. 2013. Slavery in the City: Death of 21-year-old Intern Moritz Erhardt at Merrill Lynch Sparks Furore Over Long Hours and Macho Culture at Banks. The Independent. Accessed November 3, 2013. http://www.independent.co.uk/news/uk/home-news/slavery-in-the-city-death-of21 yearold-intern-moritz-erhardt-at-merrill-lynch-sparks-furore-over-long-hours-and-macho-cultureat-banks-8775917.html.

Gregg, Melissa. 2011. Work's Intimacy. Cambridge: Polity Press.

Harvey, Lee. 2000. New Realities: The Relationship between Higher Education and Employment. Tertiary Education and Management 6 (1): 3-17.

Heelas, Paul. 2002. Work Ethics, Soft Capitalism, and the "Turn to Life." In Cultural Economy: Cultural Analysis and Commercial Life, edited by Paul du Gay and Michael Pryke, 78-97. London: Sage.

Hewlett, Sylvia Ann. 2007. Is Your Extreme Job Killing You? Harvard Business Review. Accessed November 12, 2014. https://hbr.org/2007/08/is-your-extreme-job-killing-yo.

Hewlett, Sylvia Ann and Carolyn Buck Luce. 2006. Extreme Jobs: The Dangerous Allure of the 70Hour Workweek. Harvard Business Review 84 (12): 49-59.

Kellner, Hansfried and Frank Heuberger. 1994. Hidden Technocrats: The New Class and New Capitalism. New Brunswick, NJ: Transaction Publishers.

Kennedy, Maev. 2013. Bank Intern Moritz Erhardt Died from Epileptic Seizure, Inquest Told. The Guardian. November 23. Accessed June 27, 2014. http://www.theguardian.com/business/2013/nov/22/moritz-erhardt-merrill-lynch-intern-dead-inquest.

Kuehn, Kathleen and Thomas F. Corrigan. 2013. Hope Labor: The Role of Employment Prospects in Online Social Production. The Political Economy of Communication 1(1). Accessed October 13, 2014. http://www.polecom.org/index.php/polecom/article/view/9.

Labour Party (Great Britain). 1997. New Labour, Because Britain Deserves Better. London: Labour Party.

Lewis, Charlton Thomas and Charles Short. 1879. A Latin Dictionary. Revised and enlarged edition. Oxford: Clarendon Press.

Malik, Shiv. 2013. Moritz Erhardt Intern Death Spurs Bank of America Merrill Lynch Review. The Guardian. August 23. Accessed June 27, 2014. http://www.theguardian.com/business/2013/aug/23/intern-death-bank-of-america-merrill-lynch.

Marx, Karl. 1973. Grundrisse: Foundations of the Critique of Political Economy. London: Penguin Classics.

Maslow, Abraham H. 1954. Motivation and Personality. New York: Harper \& Row.

Nonaka, Ikujiro and Hirotaka Takeuchi. 1995. The Knowledge-Creating Company: How Japanese Companies Create the Dynamics of Innovation. Oxford: Oxford University Press.

Nucleargraduates.com. 2009. Our Sponsor Organizations | nucleargraduates. Accessed July 1, 2014. http://www.nucleargraduates.com/introduction/our-sponsor-organisations/.

O'Connor, Ellen. 1999. Minding the Workers: The Meaning of "Human" and "Human Relations" in Elton Mayo. Organization 6 (2): 223-246.

Paine, Carina and Sue Honore. 2011. Great Expectations: Managing Generation Y. Institute of Leadership \& Management and Ashridge Business School.

Paton, Graeme. 2014. Four-in-10 Graduate Jobs "Reserved for Student Interns." The Telegraph. January 13. Accessed June 28, 2014. http://www.telegraph.co.uk/education/educationnews/10566757/Four-in-10-graduate-jobsreserved-for-student-interns.html.

Rose, Nikolas. 1999a. Governing the Soul: The Shaping of the Private Self. London: Free Association Books.

Rose, Nikolas. 1999b. Powers of Freedom: Reframing Political Thought. Cambridge: Cambridge University Press.

Steiner, George. 2007. Interview, Part Two. Accessed 13 December 2014. https://www.youtube.com/watch?v=HPtJeGo0P6w.

Thrift, Nigel. 2000. Performing Cultures in the New Economy. Annals of the Association of American Geographers 90 (4): 674-692.

Thrift, Nigel. 1997. The Rise of Soft Capitalism. Journal for Cultural Research 1(1): 29-57. 
Tipton, Steven M. 1984. Getting Saved from the Sixties: Moral Meaning in Conversion and Cultural Change. Stanford: University of California Press.

Weeks, Kathi. 2011. The Problem with Work: Feminism, Marxism, Antiwork Politics, and Postwork Imaginaries. Durham, NC: Duke University Press.

Wright, Ben. 2014. Bank of America Eases Work Conditions For Junior Staff. Wall Street Journal. January 10. Accessed 28 June 2014.

http://online.wsj.com/news/articles/SB10001424052702303393804579312503858867722.

\section{About the Authors}

Bogdan Costea

Bogdan Costea is a Reader in the Department of Organisation, Work, and Technology at Lancaster University's Management School. He pursues three main lines of investigation: subjectivity, work, and managerialism in the context of modernity. They are connected by a common thread linking the growth of Human Resources Management during the past three decades with wider developments in the social sciences and the humanities.

Peter Watt

Peter Watt is a Lecturer in Business Management at York St. John University. His current research draws on contemporary literary fiction to explore the way in which the figure of "the graduate" has become an exemplary theme in which managerial tropes and popular understandings of value come together and intersect.

Kostas Amiridis

Kostas Amiridis is a Lecturer in the Department of Organisation, Work, and Technology at Lancaster University's Management School. His research focuses on the evolution and limits of business ethics, human resource management, and the history of management thought. 